\title{
Synthesis of ZnO Nanostructures by Hydrothermal Method
}

\section{Pantelitsa Georgiou, Konstantinos Kolokotronis and Johannis Simitzis*}

National Technical University of Athens, School of Chemical Engineering, Department III, Materials

Science and Engineering, Laboratory Unit "Advanced and Composite Materials", 9 Heroon

\author{
Polytechniou str., Zografou Campus, 15773 Athens, Greece \\ *simj@chemeng.ntua.gr (corresponding author)
}

Submitted: April 10, 2009; Revised: June 2, 2009; accepted: June 4, 2009

Keywords: ZnO nanostructures, hydrothermal method, XRD, SEM

Abstract. $\mathrm{ZnO}$ was synthesized by the hydrothermal method using proper aqueous solutions of
$\mathrm{ZnCl}_{2}$ and $\mathrm{NaOH}$, as the main raw materials, corresponding to the molar ratio of $\mathrm{Zn}^{2+}: \mathrm{OH}^{-}=1: 20$
(solution ' $\mathrm{A}$ '), and a proper proportion of water as solvent, ethanol (EtOH) as non solvent and
polyethylene glycol (PEG) as nonionic surfactant (solution 'B'). The reaction takes place in an
autoclave at $200{ }^{\circ} \mathrm{C}$ for a defined period of time $(1-20 \mathrm{~h}$ ). The solid $\mathrm{ZnO}$ products received after
centrifugation, washing and drying were characterized by X-ray diffraction (XRD) and Scanning
Electron Microscopy (SEM). The percentage of unreacted $\mathrm{Zn}$ present after the reaction in the liquid
phase (incumbent solution) was determined by Atomic Absorption Spectroscopy. The parameters of
processing (i.e., temperature, pressure, residence time) and the raw materials parameters (i.e.
proportion of $\frac{\text { Solution 'A' }}{\mathrm{mL} \mathrm{H}_{2} \mathrm{O}+\mathrm{mL} \text { EtOH }}$, amount of PEG) influence the morphology and the dimensions of the product. Increasing the residence time from $1 \mathrm{~h} \rightarrow 3 \mathrm{~h} \rightarrow 20 \mathrm{~h}$, the amorphous regions illustrated in SEM images are decreased and the number and dimensions of the obtained single or branched rods of the final product are increased. Avoiding the use of additional water, i.e. the denominator in the aforementioned ratio, $\mathrm{mL}$, water, is equal to zero, but simultaneously using ethanol, the $\mathrm{ZnO}$ material is mainly amorphous. Increasing the amount of the additional water without ethanol, no amorphous material is observed and single rods or flowerlike/starlike structures having ends of regular hexagonal pyramid structure, are formed. Increasing the proportion of PEG, many flowerlike or starlike branched structures having ends of regular hexagonal prismatic structure, are formed. The $\mathrm{ZnO}$ materials having much of amorphous regions do not show XRD peaks. On the other hand, the crystalline $\mathrm{ZnO}$ materials show many XRD peaks, which are indexed and they correspond to the wurtzite-structured (hexagonal) ZnO. Furthermore, the lattice constants $\alpha$ and $\mathrm{c}$ are determined.

\section{Introduction}

Zinc oxide $(\mathrm{ZnO})$ is an important multifunctional semiconductor with a wide bandgap (3.4 eV). It has a stable wurtzite structure with lattice spacing of $\mathrm{a}=0.325 \mathrm{~nm}$ and $\mathrm{c}=0.521 \mathrm{~nm}$ [1-4]. It has attracted much research interest due to its unique optical, acoustic, luminescent, electronic and optoelectronic properties. Until now, many methods have been used to prepare the $\mathrm{ZnO}$ material as one-dimensional (1D) nanostructures with different morphologies including nanowires, nanorods, nanotubes, whiskers, nanocrystals, nanobelts and other superstructures $[1,3,5]$. They represent a broad class of nanoscale building blocks that have been used to assemble functional devices such as lasers, photodetectors, field emitters, acoustic and short wavelength optical devices, gas sensors, piezoelectric transducers and actuators, solar cells etc [3,5-8].

There are several methods to synthesize $\mathrm{ZnO}$ nanostructures, such as vapour transport process catalyst free (vapour-solid process / VS) or catalyst assisted (vapour-liquid-solid process / VLS), epitaxial electrodeposition (ED), sol-gel method, polymer assisted growth, metal-organic chemical 
vapour deposition (MOCVD), pulsed laser deposition (PLD), aqueous chemical methods and hydrothermal methods $[1,7,8]$. Low temperature hydrothermal synthesis (at $95{ }^{\circ} \mathrm{C}$ or between $150-$ $250{ }^{\circ} \mathrm{C}$ ) [9-11] is becoming popular for environmental reasons, since water is used as the reaction solvent than organics [12]. This method is also more convenient and economic for large-scale preparation of well-ordered $\mathrm{ZnO}$ nanowire/nanorod arrays compared to VLS, CVD and ED methods, which require sophisticated equipment and rigorous conditions (such as single-crystalline substrates) [10].

The aim of this work is firstly to synthesize $\mathrm{ZnO}$ nanostructures by hydrothermal method and secondly to investigate the influence of processing parameters (temperature, pressure, residence time) and of raw materials parameters (additional water, ethanol $(\mathrm{EtOH})$ and polyethyleneglycole (PEG)) on the morphology / dimensions and structure of the final products.

\section{Experimental}

The first step is the preparation of the aqueous solutions of $10 \mathrm{M} \mathrm{NaOH}$ and $0.5 \mathrm{M} \mathrm{ZnCl}_{2}$ using bidistilled water. The two solutions are mixed together under constant magnetic agitation for the preparation of the homogenous solution ' $\mathrm{A}$ ' with the desired molar ratio of $\mathrm{Zn}^{2+}: \mathrm{OH}^{-}=1: 20$. Another homogenous solution ' $\mathrm{B}$ ' is prepared by mixing, under constant magnetic agitation, water, ethanol $(\mathrm{EtOH})$ and polyethylene glycol (PEG) in proper proportion. If the PEG is not fully dissolved at room temperature, the mixing under magnetic agitation is continued with mild heating, without the temperature to exceed $50{ }^{\circ} \mathrm{C}$. A defined volume $(\mathrm{mL})$ from solution ' $\mathrm{A}$ ' is transferred into a glass vessel and is ultrasonically treated for $45 \mathrm{~min}$ and then is mixed with solution ' $\mathrm{B}$ '. The final mixture is transferred to a $(500 \mathrm{~mL})$ Teflon vessel and placed in the autoclave, which is then sealed. The autoclave is heated up to $200{ }^{\circ} \mathrm{C}$ with a rate of about $4.5^{\circ} \mathrm{C}$ per min, using a temperature controller. The hydrothermal treatment of the solution is carried out at $200^{\circ} \mathrm{C}$ for defined time (from 1 to $20 \mathrm{~h}$ ), with almost constant pressure. After the completion of the desired reaction time, the heating controller is shut off and the autoclave is let alone to cool down to room temperature and to drop the pressure. The cooling process takes hours to complete, which is also important for the formation of $\mathrm{ZnO}$ structures. Then, the autoclave is unsealed and inside the Teflon vessel there are two phases, one liquid (incumbent solution) and one solid at the bottom as precipitate. This product, in the form of white fine powder, is received by centrifugation (6000 rpm for $15 \mathrm{~min})$ and is thoroughly washed with bidistilled water (or ethanol in case the solution ' $\mathrm{B}$ ' is prepared without water), and then is dried. Finally, the product is weighted and stored in a plastic vessel.

The solid $\mathrm{ZnO}$ products were characterized by X-ray diffraction (XRD), using a Siemens D5000 X-Ray Diffractometer and by Scanning Electron Microscopy (SEM), using a FEI Quanta 200 scanning electron microscope. The morphology is observed on SEM images and the dimensions of the $\mathrm{ZnO}$ forms are measured. Their structure is characterized based on their XRD patterns. Furthermore, the incumbent solution is analyzed with Atomic Absorption Spectroscopy (AAS) (Perkin-Elmer, model 330) to evaluate the percentage of unreacted $\mathrm{Zn}$ in the reaction mixture.

\section{Results and Discussion}

Table 1 presents the raw materials used, their proportions and the conditions during their hydrothermal treatment for the synthesis of $\mathrm{ZnO}$. Two series of $\mathrm{ZnO}$ materials are prepared with the proportion of

$$
\frac{\text { Solution 'A' }}{\mathrm{mL} \mathrm{H}_{2} \mathrm{O}+\mathrm{mL} \mathrm{EtOH}} \text { equal to } \frac{10}{70} \frac{\mathrm{mL}}{\mathrm{mL}}
$$

for both series. By mixing the proper volume of aq. solution of $\mathrm{NaOH}(10 \mathrm{M})$ with that of $\mathrm{ZnCl}_{2}$ $(0.5 \mathrm{M})$, the proportion of $\mathrm{Zn}^{2+}: \mathrm{OH}^{-}$is kept equal to $1: 20 \mathrm{~mol} / \mathrm{mol}$ for both series of $\mathrm{ZnO}$ materials. The latter proportion is chosen based on preliminary experiments. The mixing of both solutions in specific concentrations and volumes to prepare a solution having the ratio of $\mathrm{Zn}^{2+}: \mathrm{OH}^{-}$ 
$=1: 8 \mathrm{~mol} / \mathrm{mol}$ is not acceptable, due to partial solubility. Full solubility begins for $\mathrm{Zn}^{2+}: \mathrm{OH}^{-}=1$ : $16 \mathrm{~mol} / \mathrm{mol}$. Hydrothermal experiments proved that the molar ratio of $\mathrm{Zn}^{2+}: \mathrm{OH}^{-}=1: 20 \mathrm{~mol} / \mathrm{mol}$ is favorable. Concerning the conditions of the hydrothermal treatment, the use of ethanol in the reaction mixture, results in higher pressures in the autoclave, during the heating.

Table 1. Raw materials and conditions for the hydrothermal synthesis of $\mathrm{ZnO}$ nanostructures

\begin{tabular}{|c|c|c|c|c|c|c|c|}
\hline \multicolumn{2}{|c|}{$\begin{array}{c}\text { Code of } \\
\text { Materials }\end{array}$} & \multirow{3}{*}{$\begin{array}{c}\text { Solution 'A' } \\
10 \mathrm{M} \mathrm{NaOH}^{\prime} \\
0.5 \mathrm{M} \mathrm{ZnCl}_{2} \\
(\text { molar ratio of } \\
\left.\mathrm{Zn}^{2+}: \mathrm{OH}^{-}=1: 20\right) \\
{[\mathrm{mL}]}\end{array}$} & \multicolumn{3}{|c|}{ Solution 'B' } & \multicolumn{2}{|c|}{$\begin{array}{c}\text { Hydrothermal Treatment } \\
\text { at } 200^{\circ} \mathrm{C}\end{array}$} \\
\hline & & & \multirow{2}{*}{$\begin{array}{l}\mathrm{H}_{2} \mathrm{O} \\
{[\mathrm{mL}]}\end{array}$} & \multirow{2}{*}{$\begin{array}{c}\text { Ethanol } \\
(\text { EtOH) } \\
{[\mathrm{mL}]}\end{array}$} & \multirow{2}{*}{$\begin{array}{c}\text { Polyethylene } \\
\text { glycol } \\
\text { (PEG) } \\
\\
{[\mathrm{g}]}\end{array}$} & & \\
\hline & & & & & & $\begin{array}{c}\text { Pressure } \\
\text { [bar] }\end{array}$ & $\begin{array}{c}\text { Residence } \\
\text { Time } \\
{[\mathrm{h}]}\end{array}$ \\
\hline \multirow{4}{*}{$\begin{array}{l}\infty \\
0 \\
0 \\
\infty \\
\infty \\
\infty \\
\infty\end{array}$} & $1 Z-1$ & 10 & 20 & 50 & 0,02 & 10 & 1 \\
\hline & $1 Z-3$ & 10 & 20 & 50 & 0,02 & 10 & 3 \\
\hline & $5 Z-1$ & 10 & 20 & 50 & 1,60 & 11 & 1 \\
\hline & $4 Z-1$ & 10 & - & 70 & 0,16 & 21.5 & 1 \\
\hline \multirow{4}{*}{ 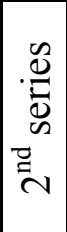 } & $2 Z-1$ & 15 & 105 & - & 0,03 & 7 & 1 \\
\hline & $2 Z-3$ & 15 & 105 & - & 0,03 & 7 & 3 \\
\hline & $2 Z-20$ & 15 & 105 & - & 0,03 & 7 & 20 \\
\hline & $9 Z-1$ & 15 & 105 & - & - & 7 & 1 \\
\hline
\end{tabular}

According to literature [5] the growth unit of $\mathrm{ZnO}$ crystal is the complex $\mathrm{Zn}(\mathrm{OH})_{4}^{2-}$. The formation mechanism of $\mathrm{ZnO}$ crystallite under hydrothermal condition begins with the formation of the growth unit:

$$
\mathrm{Zn}^{2+}+4 \mathrm{OH}^{-}=\mathrm{Zn}(\mathrm{OH})_{4}^{2-}
$$

and proceeds with the incorporation of growth unit into the newly formed crystal lattice by the oxolation reaction under supersaturation condition :

$\mathrm{Zn}(\mathrm{OH})_{4}^{2-}+\mathrm{Zn}(\mathrm{OH})_{4}^{2-}=\mathrm{Zn}_{2} \mathrm{O}(\mathrm{OH})_{6}^{4-}+\mathrm{H}_{2} \mathrm{O}$

$\mathrm{Zn}_{\mathrm{x}} \mathrm{O}_{\mathrm{y}}(\mathrm{OH})_{\mathrm{z}}^{(\mathrm{z}+2 \mathrm{y}-2 \mathrm{x})}+\mathrm{Zn}(\mathrm{OH})_{4}^{2-}=\mathrm{Zn}_{\mathrm{x}+1} \mathrm{O}_{\mathrm{y}+1}(\mathrm{OH})_{\mathrm{z}+2}^{(\mathrm{z}+2 \mathrm{y}-2 \mathrm{x}+2)-}+\mathrm{H}_{2} \mathrm{O}$

Finally, when the size of the clusters $\mathrm{Zn}_{\mathrm{x}+1} \mathrm{O}_{\mathrm{y}+1}(\mathrm{OH})_{\mathrm{z}+2}^{(\mathrm{z}+2 \mathrm{y}-2 \mathrm{x}+2)-}$ reaches the size of the so-called "critical nucleus", ZnO powders are precipitated.

For the quantification of the unreacted $\mathrm{Zn}$ present in the incumbent solution as received from the autoclave after the completion of the reaction, the procedure is as follows : the incumbent solution is volumetric measured and $1 \mathrm{~mL}$ of this solution is diluted with bidistilled water to form a diluted solution of $250 \mathrm{~mL}$ and then the percentage of unreacted $\mathrm{Zn}$ is measured with Atomic Absorption Spectroscopy (AAS). The results are presented in Table 2; the amount of $\mathrm{Zn}$ in the incumbent solution is calculated in percentage and the difference corresponds to the percentage of reacted $\mathrm{Zn}$. The yield of $\mathrm{Zn}$ is highly and is fluctuated approximately between 90 and $96 \% \mathrm{w} / \mathrm{w}$. 
Table 2. Amount of $\mathrm{Zn}$ containing in the incumbent solution determined by AAS and amount of reacted $\mathrm{Zn}$

\begin{tabular}{|c|c||c||c|}
\hline $\begin{array}{c}\text { Incumbent Solution of } \\
\text { Experiments }\end{array}$ & $\begin{array}{c}\text { Volume of the } \\
\text { Incumbent Solution } \\
{[\mathrm{mL}]}\end{array}$ & $\begin{array}{c}\text { Measured Zn in the } \\
\text { Incumbent Solution } \\
\text { by AAS } \\
{[\mathrm{ppm}=\mathrm{mg} / \mathrm{L}]}\end{array}$ & $\begin{array}{c}\text { Percentage of Reacted } \\
\mathrm{n}\end{array}$ \\
\hline $2 \mathrm{Z}-1$ & 106 & 0,397 & 95,71 \\
\hline $4 \mathrm{Z}-1$ & 49,5 & 0,758 & 94,26 \\
\hline $9 \mathrm{Z}-1$ & 110 & 0,885 & 90,01 \\
\hline
\end{tabular}

Based on the SEM images (Figs. 1-8), the final products show a growing behaviour along the caxis with morphologies of straight or flowerlike / starlike rods, either ending with regular hexagonal prism or with hexagonal pyramid. More specifically, the material 1Z-1 (Fig. 1) consists of mainly amorphous material and very few single rods or rods in branched structures deposited on it, whereas the material received after $3 \mathrm{~h}$ (Fig. 2 / 1Z-3) consists of a) single rods, b) few flowerlike or starlike branched structures and c) amorphous material covered with a) and b) forms. Additionally, most rods of this material, either single or branched have ends of regular hexagonal pyramid structure. In the material 5Z-1 (Fig. 7) there are a) single rods, b) many flowerlike or starlike branched structures and c) some amorphous material covered with a) and b) forms. It is characteristic for this material that the rods, branched or not, have ends of regular hexagonal prismatic structure. The material 4Z1 (Fig. 6) consists of a) very few single rods, b) very few branched rods and c) much of amorphous material. All rods of this material branched or not, have sharp ends. In Fig. 3, the material 2Z-1 consists of a) single rods, b) few flowerlike or starlike branched structures and c) a tuft made of oriented whiskers; the same material received after $3 \mathrm{~h}$ (Fig. 4 / 2Z-3) or $20 \mathrm{~h}$ (Fig. 5 / 2Z-20) gives similar products of a) single rods and b) flowerlike or starlike branched structures. Additionally, most rods of this material, either single or branched, have ends of regular hexagonal pyramid structure and the oriented whiskers of the tuft have sharp ends. Finally, the material 9Z-1 (Fig. 8) consists of a) single rods, b) flowerlike or starlike branched structures and c) some amorphous material covered with a) and b) forms. The rods of this material branched or not, have ends of regular hexagonal pyramid structure.
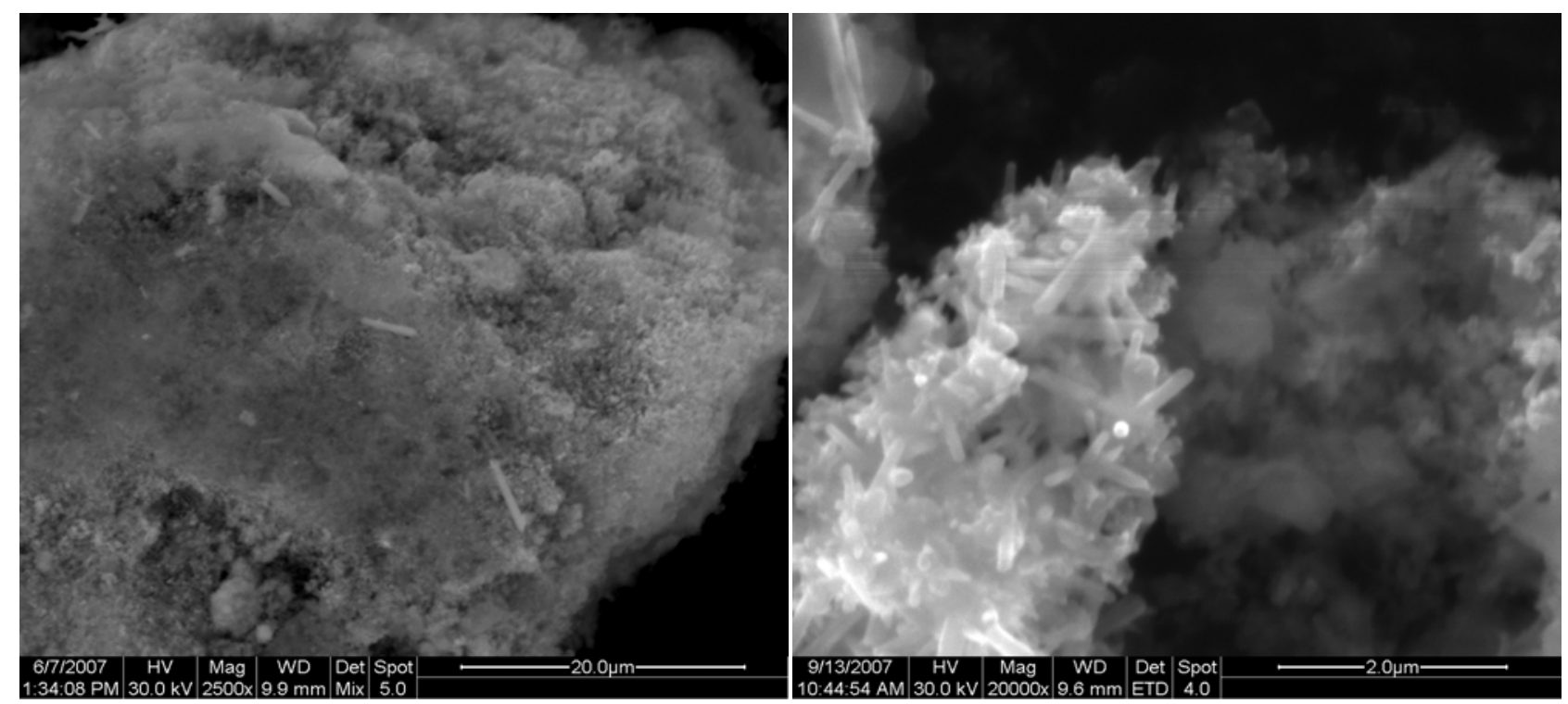

Fig. 1. SEM images of material 1Z-1. 


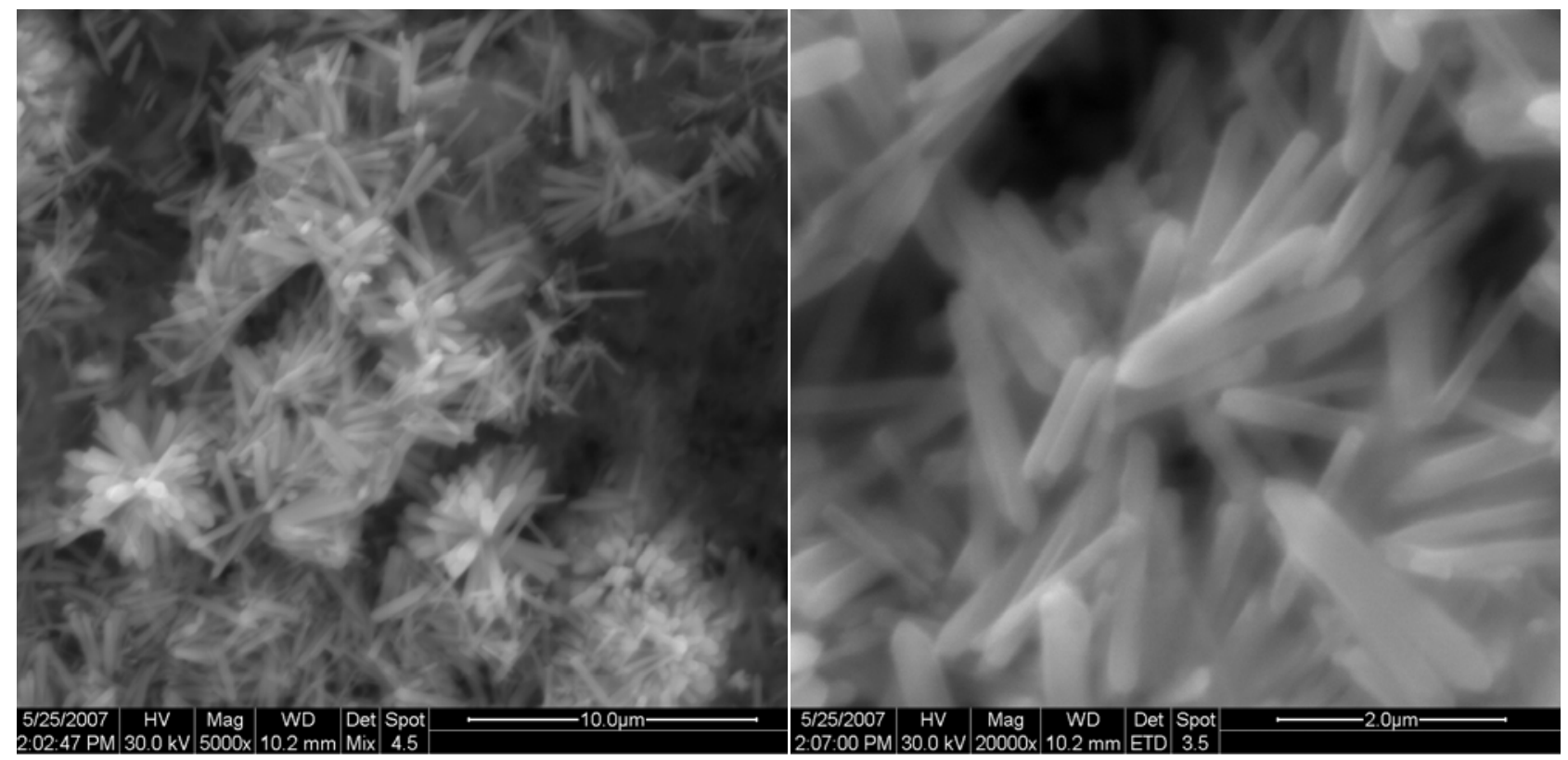

Fig 2. SEM images of material 1Z-3.

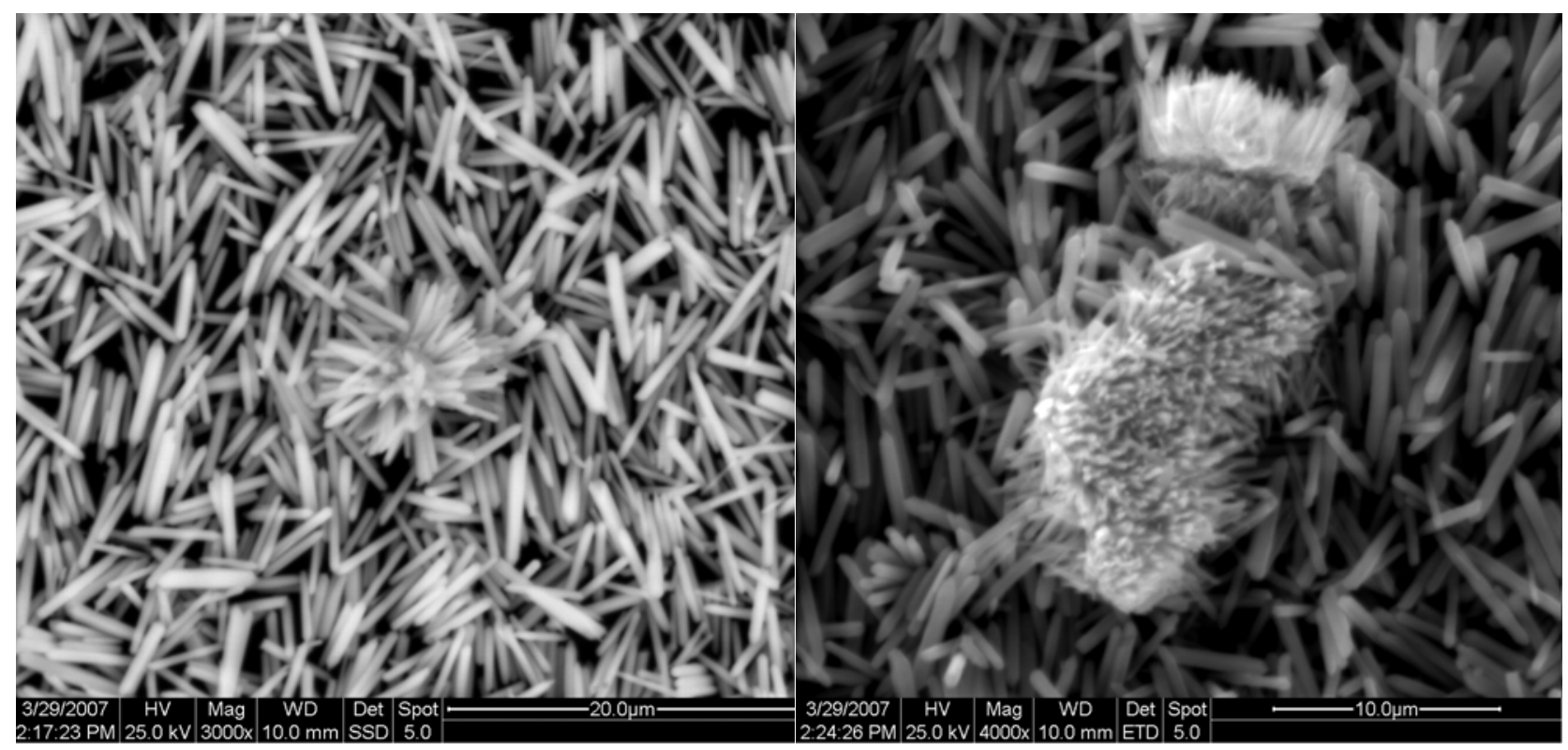

Fig 3. SEM images of material 2Z-1. 


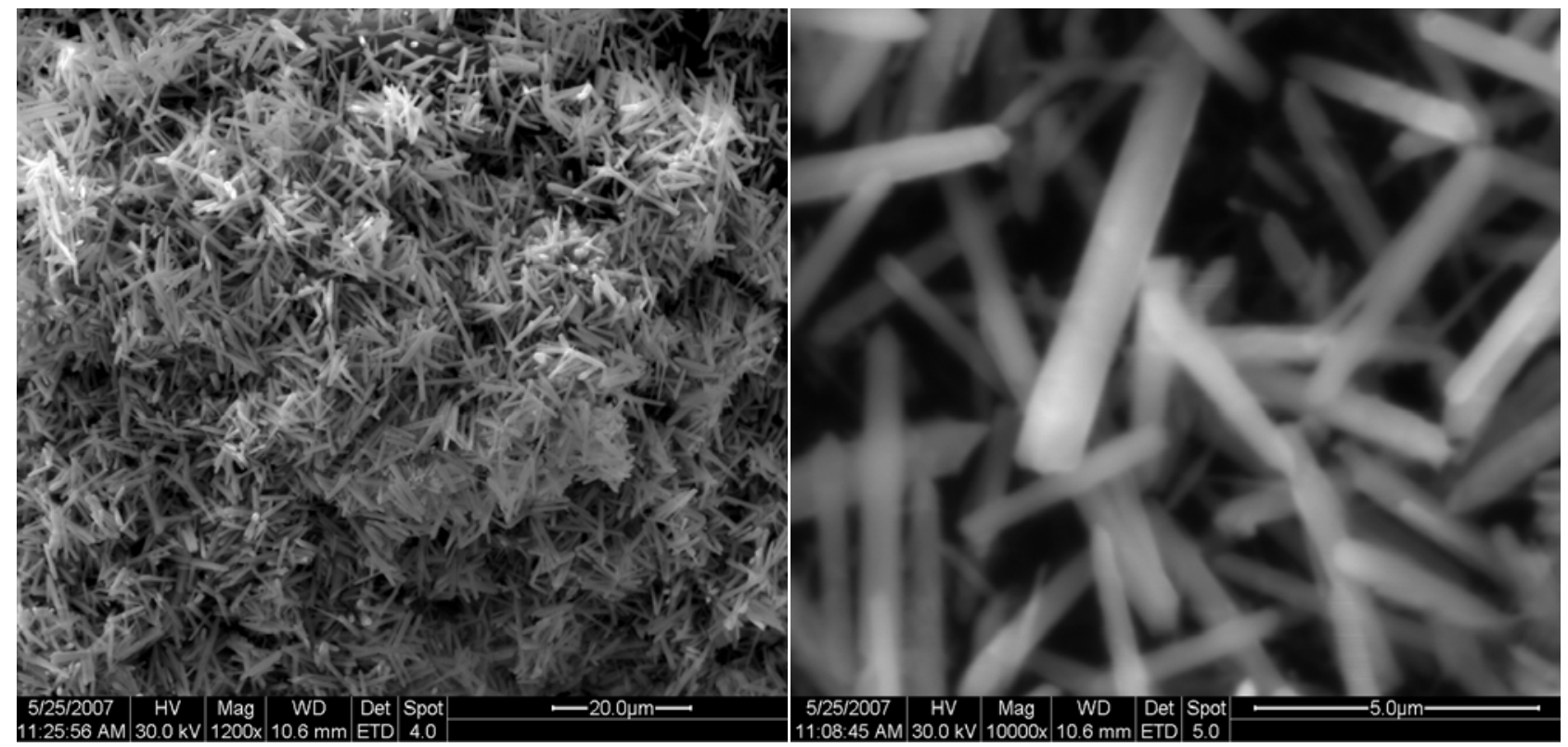

Fig 4. SEM images of material 2Z-3.

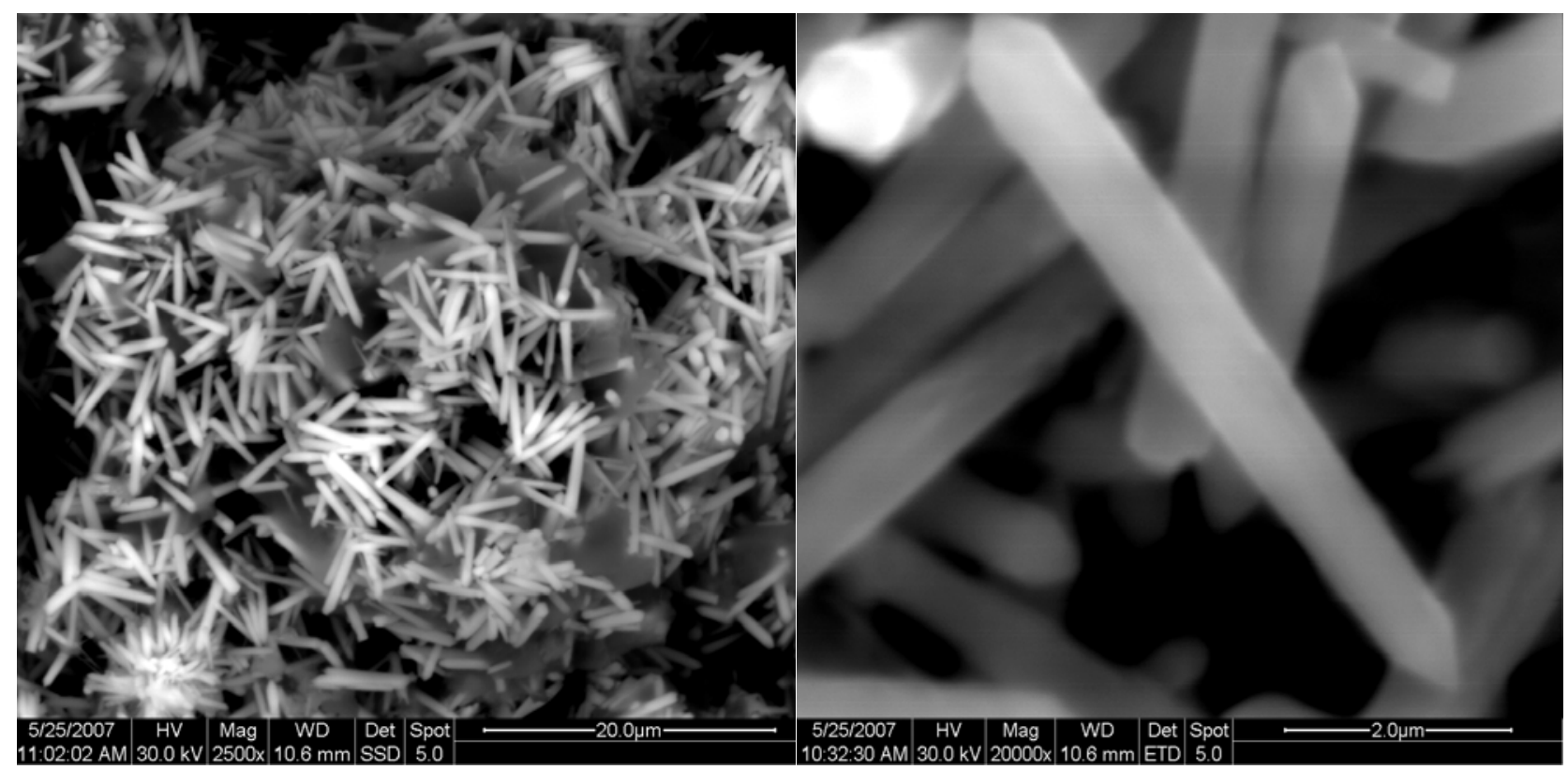

Fig 5. SEM images of material 2Z-20. 


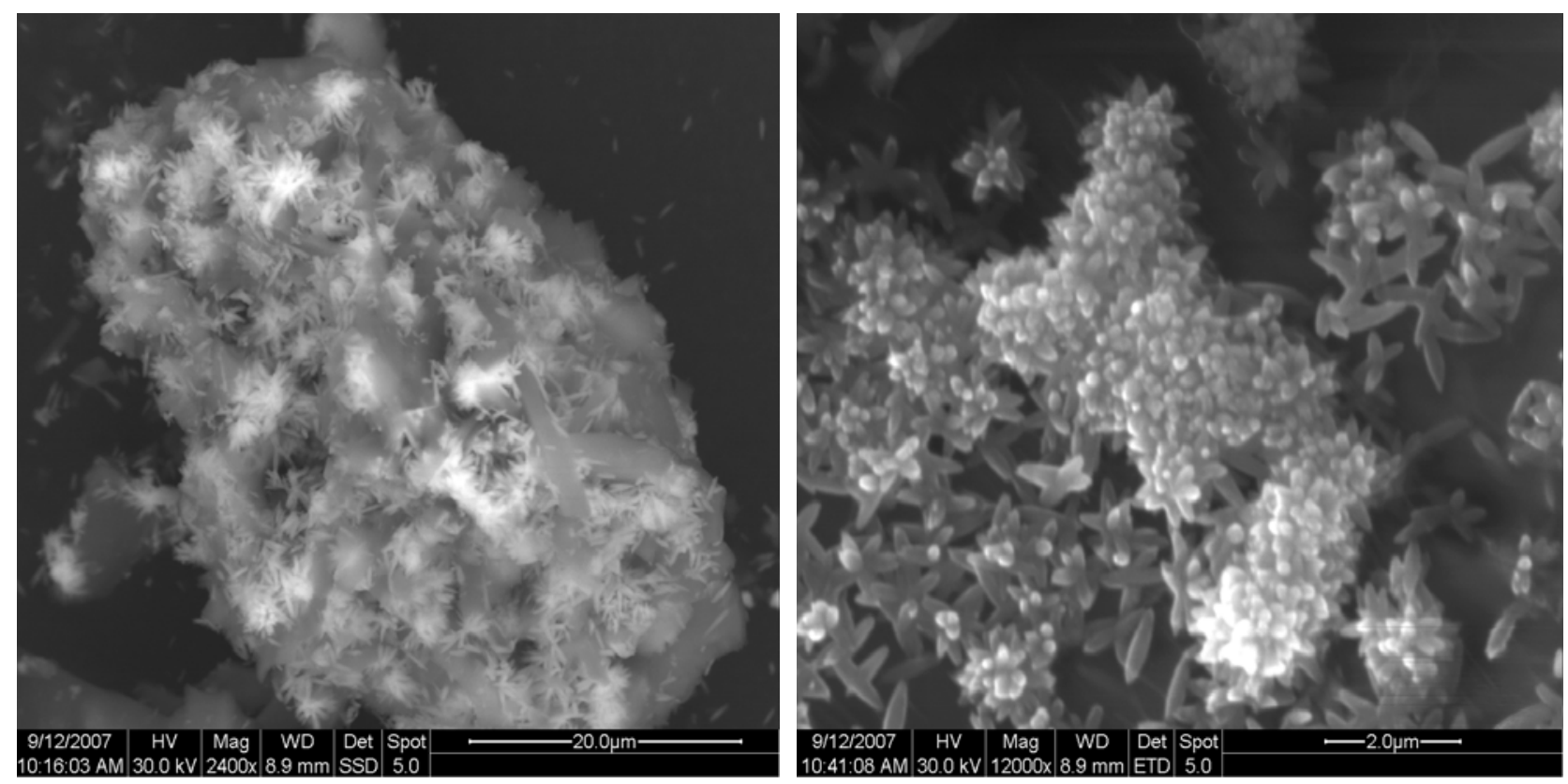

Fig. 6. SEM images of material 4Z-1.

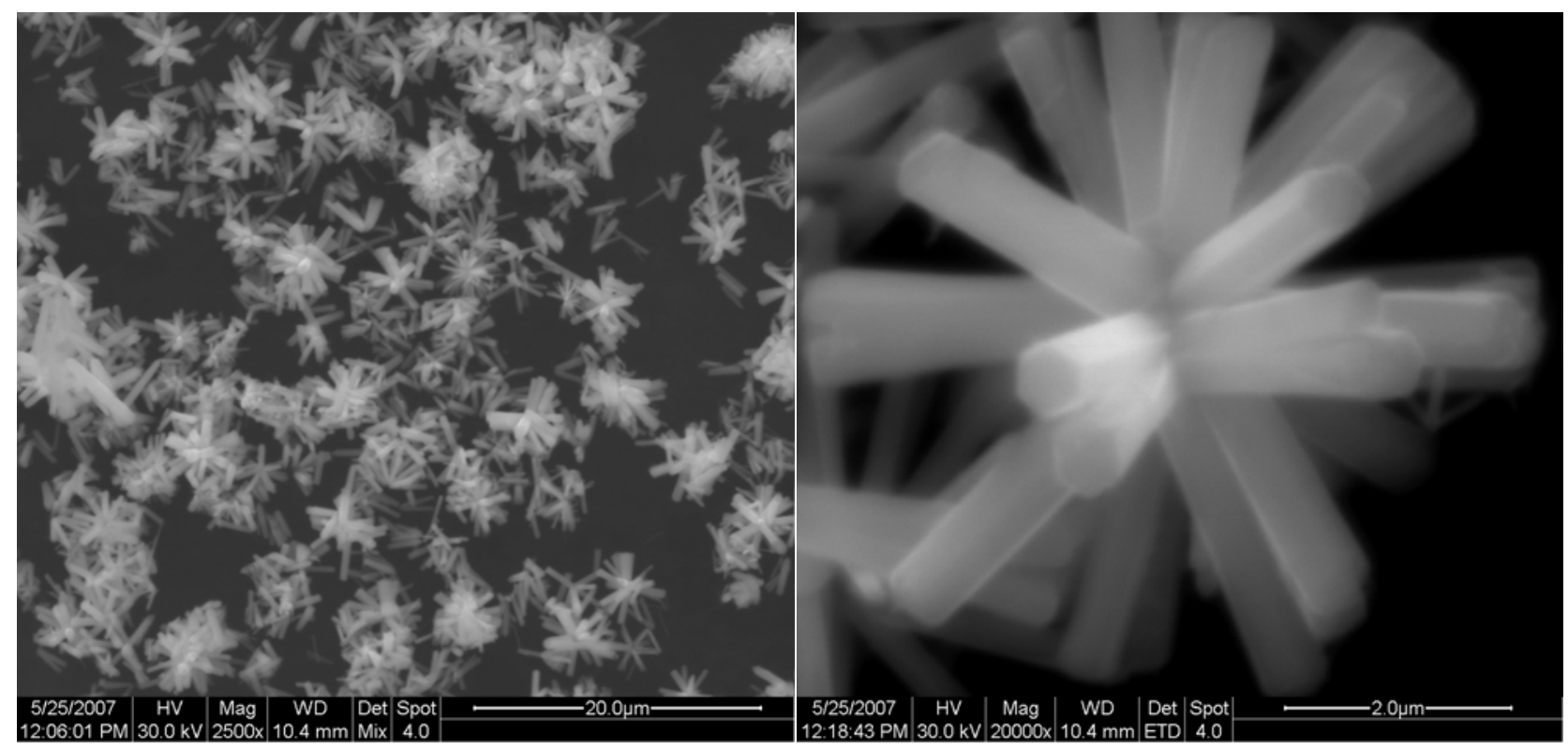

Fig 7. SEM images of material 5Z-1. 

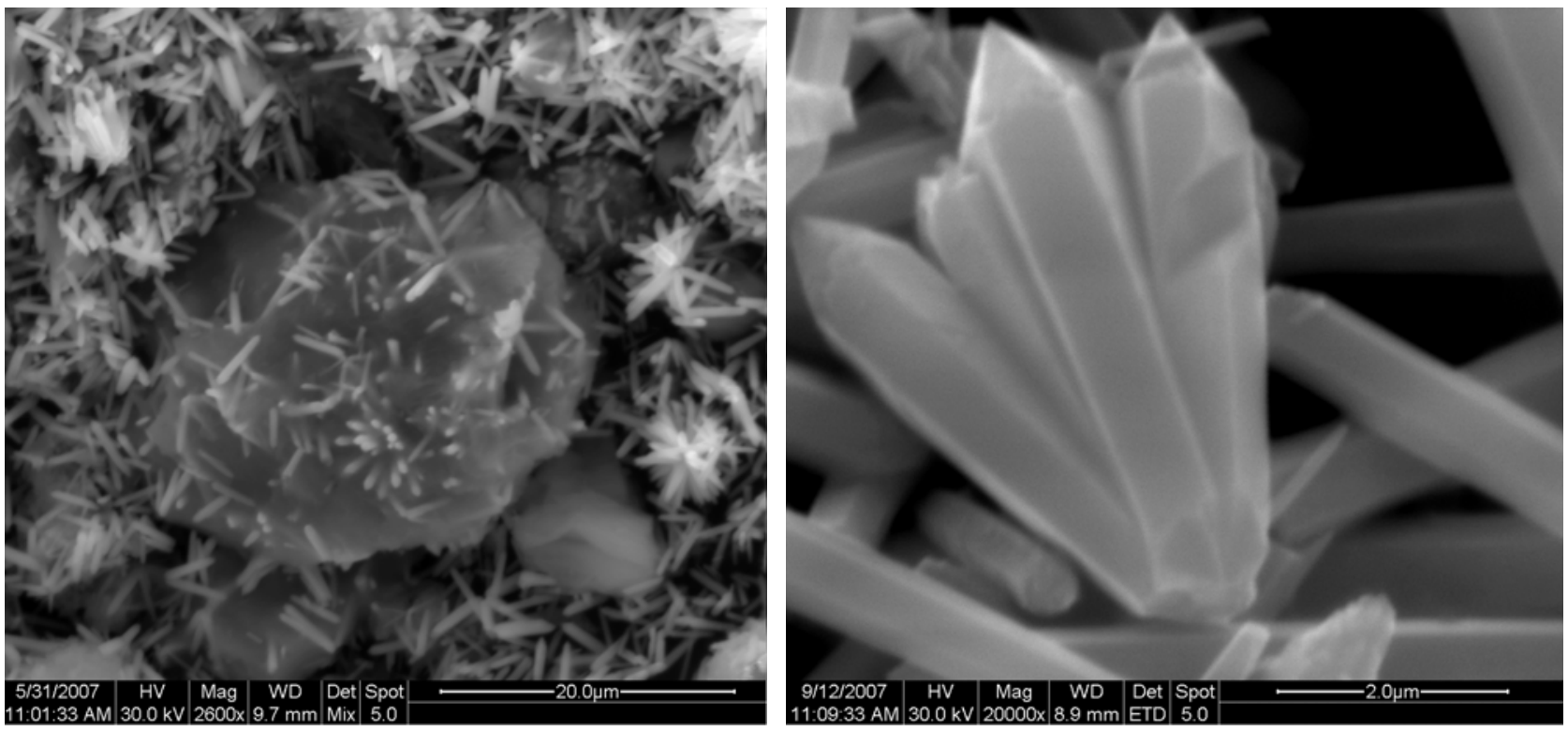

Fig. 8. SEM images of material 9Z-1.

$\mathrm{ZnO}$ particle dimensions of the diameter (D) in $\mathrm{nm}$ and the length (L) in $\mu \mathrm{m}$ are summarized in Table 3.

Table 3. ZnO particle dimensions.

\begin{tabular}{|c|c|c|}
\hline \multirow{2}{*}{$\begin{array}{c}\text { Code of } \\
\text { Materials }\end{array}$} & \multicolumn{2}{|c|}{ Particle Dimensions } \\
\hline & $\begin{array}{l}\text { Diameter (D) } \\
{[\mathrm{nm}]}\end{array}$ & $\begin{array}{l}\text { Length }(\mathrm{L}) \\
\quad[\mu \mathrm{m}]\end{array}$ \\
\hline $1 \mathrm{Z}-1$ & $\begin{array}{l}\text { single rods and branched rods: } \\
\text { from } 80 \text { to } 200\end{array}$ & from 0,4 to 1 \\
\hline $1 Z-3$ & $\begin{array}{l}\text { a) single rods from: } 130 \text { to } 400 \\
\text { b) branched rods: } 400\end{array}$ & a) from 1 to 4 \\
\hline $5 Z-1$ & $\begin{array}{l}\text { a) single rods: from } 170 \text { to } 500 \\
\text { b) branched rods: from } 170 \text { to } 670\end{array}$ & $\begin{array}{l}\text { a) from } 1,3 \text { to } 2,5 \\
\text { b) from } 1,8 \text { to } 2\end{array}$ \\
\hline $4 Z-1$ & $\begin{array}{l}\text { a) single rods: from } 100 \text { to } 280 \\
\text { b) branched rods: from } 100 \text { to } 230\end{array}$ & a) from 0,8 to 1,1 \\
\hline $2 Z-1$ & $\begin{array}{l}\text { a) single rods: from } 330 \text { to } 800 \\
\text { b) branched rods: from } 420 \text { to } 670 \\
\text { c) tuft whiskers: } 160 \text { and smaller }\end{array}$ & a) from 1,8 to 8,9 \\
\hline $2 Z-3$ & $\begin{array}{l}\text { single rods and branched rods: } \\
\text { from } 270 \text { to } 800\end{array}$ & from 4 to 6,4 \\
\hline $2 Z-20$ & $\begin{array}{l}\text { single rods and branched rods: } \\
\text { from } 270 \text { to } 800\end{array}$ & from 4 to 6,4 \\
\hline $9 Z-1$ & $\begin{array}{l}\text { a) single rods: from } 330 \text { to } 730 \\
\text { b) branched rods: from } 530 \text { to } 670\end{array}$ & $\begin{array}{l}\text { a) from } 2,7 \text { to } 4,7 \\
\text { or to } 16,7\end{array}$ \\
\hline
\end{tabular}

According to Tables 1 and 3 and the SEM images (Fig.1-8), useful conclusions arise concerning the parameters of the hydrothermal process. Increasing the residence time, the amorphous regions are decreased and more rods, branched or not, with ends of regular hexagonal pyramid structure are formed and their dimensions are increased (comparison between 1Z-1 and 1Z-3). Increasing the proportion of PEG, the amorphous regions are further reduced and many flowerlike or starlike branched structures are formed which have ends of regular hexagonal prismatic structure 
(comparison between 1Z-1 and 5Z-1). According to literature [16], the use of nonionic surfactant substances (PVA, PEG etc.) has a great influence on the final $\mathrm{ZnO}$ product. When the consistence of them is less than the CMC (CMC is the abbreviation of the critical micelle consistence) the surfactant molecules could assemble like rod-micelle and thus, these PEG solutes wrap around the $\mathrm{ZnO}$ nanoparticles when $\mathrm{ZnO}$ crystals grow up along these chains. Finally, the use of ethanol without additional water (4Z-1) leads to very few single or branched rods and much of amorphous material. Therefore additional water is necessary to be used in the initial solution for the hydrothermal process (comparison between 1Z-1 and 4Z-1). The use of increased amount of additional water, without ethanol (materials 2Z-1, 2Z-3, 2Z-20, 9Z-1) leads to the formation of nanostructured material without amorphous regions, in the forms of single or branched rods, forming flowerlike or starlike structures having ends of regular hexagonal pyramid structure. Under these conditions, $\mathrm{ZnO}$ nanostructures are sufficiently formed already by one hour, and extended time does not contribute to any improvement in the nanostructures. Comparing the $\mathrm{ZnO}$ structures of this group of materials (second group) with that of the first group (1Z-1, 1Z-3, 5Z-1, 4Z-1), it is observed that the particle dimensions are greater for the second group.

The X ray diffraction patterns of materials (a) 2Z-1 and (b) 4Z-1 are presented in Fig. 9. The Xray diffraction peaks are characterized according to literature [4,10,13-15] up to angle of $2 \vartheta$ equal to $90{ }^{\circ} \mathrm{C}$, Fig. 9(a). Above this angle, the peaks are repeated, and therefore are not characterized. All diffraction peaks are indexed and corresponded to the known wurtzite-structured (hexagonal) $\mathrm{ZnO}$, with lattice constants $\alpha$ and $\mathrm{c}$ in agreement with that of literature.

Correlating the X-ray diffraction patterns of all materials, the material 4Z-1 exhibits more amorphous than crystalline structure, Fig. 9(b). This observation is also confirmed by SEM images concluding that material 4Z-1 has much of amorphous regions. The diffractograms of materials 2Z1, 2Z-3, 2Z-20 and 9Z-1 exhibit high crystallinity. The material which is in the form of flowerlike or starlike structures (5Z-1) has a variety of orientation and a low crystallinity is observed from its diffractogram.

Furthermore, the Miller indices are calculated from peak angles and corresponded to hexagonal structure. The lattice distance $\mathrm{d}_{\mathrm{hkl}}(\AA)$ is estimated from Bragg's law [6]. In hexagonal crystal system the angles $\alpha=\beta \neq \gamma, \alpha=\beta=90^{\circ}$ and $\gamma=120^{\circ}$. The lattice constants $a=b$, and $c$ are estimated as following: For the high crystalline materials $2 Z-1: a=b=3.29 \AA, c=5.14 \AA$ and $9 Z-1: a=b=3.30 \AA$, $\mathrm{c}=5.29 \AA$, whereas generally for all materials the values vary for $\mathrm{a}=\mathrm{b}$ from $3.27 \AA$ up to $3.41 \AA$ and c from $5.01 \AA$ up to $5.37 \AA$.

Furthermore, the morphologies of straight or flowerlike/starlike $\mathrm{ZnO}$ nanorods either ending with regular hexagonal prism or with hexagonal pyramid, as derived from SEM images, are in accordance with XRD major reflexes, Fig. 9(a).

According to literature [4], the crystallographic faces (100), (101), (00 $\overline{1})$ and (001) correspond to $\mathrm{m},+\mathrm{p},-\mathrm{c}$ and $+\mathrm{c}$, accordingly (Fig. 10). The schematic representation of regular hexagonal pyramid structure $(\mathrm{p})$, regular hexagonal prism structure $(\mathrm{c})$ and side structure $(\mathrm{m})$ is shown in Fig. 10.

According to the SEM images and the XRD patterns concerning the peak diffractions at the corresponding defined Miller indices, it is concluded that the form of the materials are : 5Z-1 has ends of regular prismatic structure, 2Z-1, 2Z-3 and 2Z-20 have ends of regular pyramid structure. 

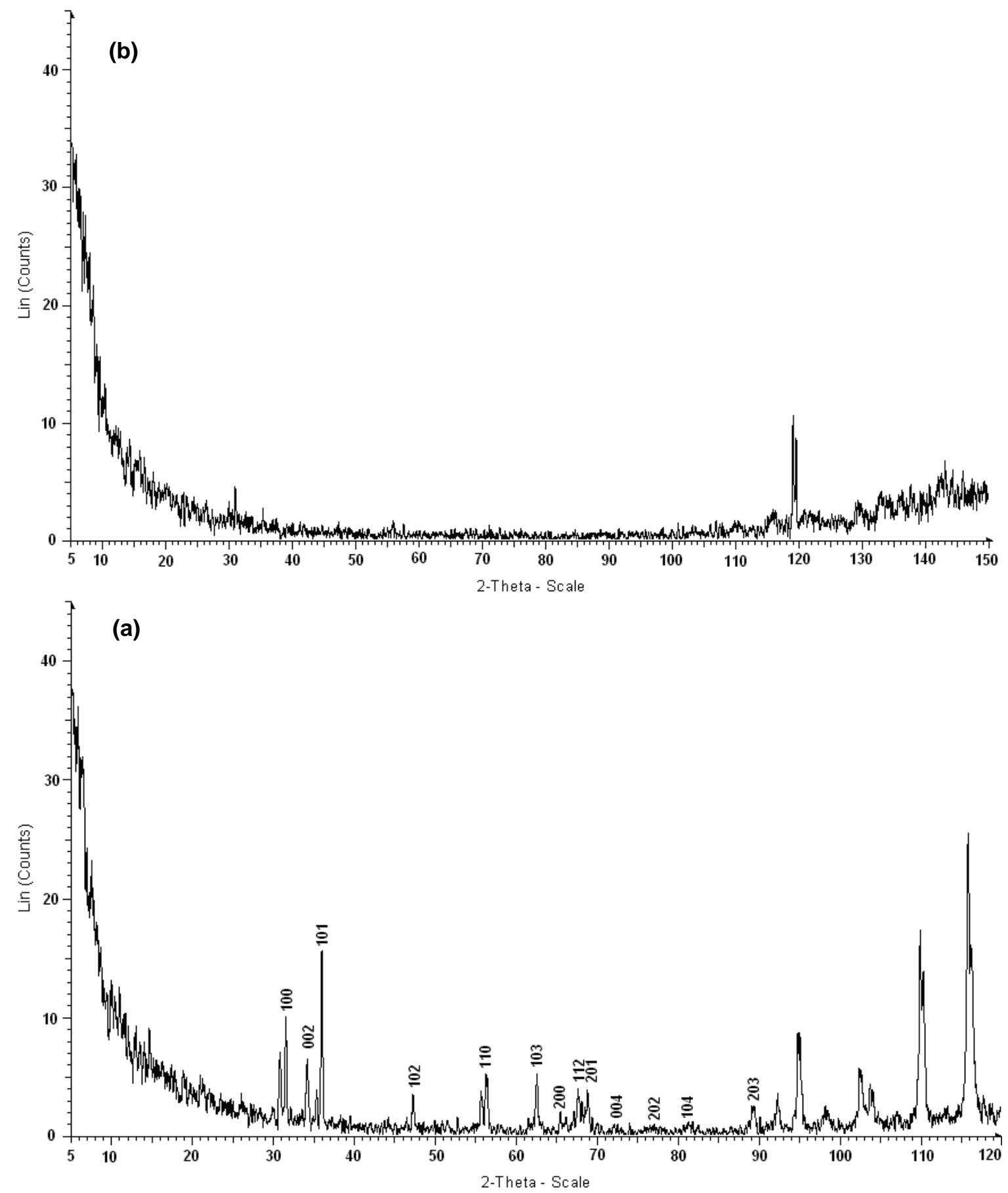

Fig. 9. X ray diffraction patterns of materials (a) 2Z-1 and (b) 4Z-1 


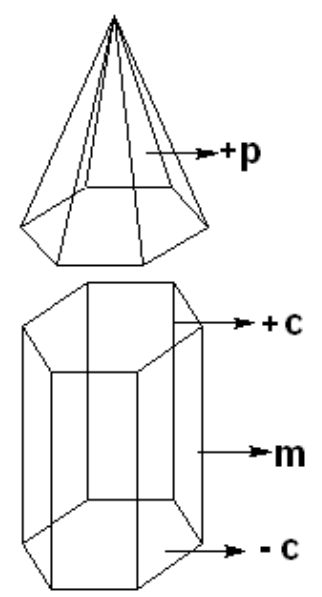

Fig. 10. Crystallographic structures. + p: regular hexagonal pyramid, $+\mathrm{c},-\mathrm{c}$ : regular hexagonal prism, m: side structure

\section{Conclusions}

Increasing the residence time from $1 \mathrm{~h} \rightarrow 3 \mathrm{~h} \rightarrow 20 \mathrm{~h}$, the amorphous regions illustrated in SEM images are decreased and the number and the dimensions of the obtained single or branched rods, of the final product are increased.

Avoiding the use of additional water but simultaneously using ethanol, the $\mathrm{ZnO}$ material is mainly amorphous. Increasing the amount of the additional water without ethanol, no amorphous material is observed and single rods or flowerlike or starlike structures having ends of regular hexagonal pyramid structure, are formed.

Increasing the proportion of PEG, many flowerlike or starlike branched structures, having ends of regular hexagonal prismatic structure, are formed.

The $\mathrm{ZnO}$ materials synthesized with the proper parameters of processing and of raw materials have sufficient yield, nanostructures with a growing behaviour along the c-axis and morphology of straight or flowerlike / starlike rods, either ending with regular hexagonal prism or with hexagonal pyramid.

\section{Literature}

[1] Z. Fan and J. G. Lu, Journal of Nanosci. Nanotechnol., Vol. 5, No. 10, (2005), p. 1561.

[2] X. Liu, X. Wu, H. Cao and R.P.H. Chang: J. Appl. Phys., Vol. 95, No.6, (2004), p. 3141.

[3] T. Gao, Q. Li and T. Wang: Chem. Mater., Vol. 17, No. 4, (2005), p. 887.

[4] W. Zheng, F. Gao, and Y. Qian: Adv. Funct. Mater., Vol. 15, No. 2, (2005), p. 331.

[5] H.S. Qian, S.H. Yu, J.Y. Gong, L.B. Luo and L.L. Wen: Crystal Growth \& Design, Vol. 5, No. 3, (2005), p. 935.

[6] X. Wu, H. Bai, C. Li, G. Lu and G. Shi: Chem. Commun., (2006), p. 1655.

[7] B. Baruwati, D.K. Kumar, S.V. Manorama: Sensors and Actuators B, Vol. 119, (2006), p. 676.

[8] A.N. Baranov, C.H. Chang, O.A. Shlyakhtin, G. N. Panin: Nanotechnology, Vol. 15, (2004), p. 1613.

[9] W.J. Li, E.W. Shi, Y.Q. Zheng, Z.W. Yin: Journal of Materials Science Letters, Vol. 20, (2001), p. 1381. 
[10]M. Guo, P. Diao and S. Cai: Journal of Solid State Chemistry, Vol. 178, (2005) p. 1864.

[11]D. Andeen, L. Loeffler, N. Padture and F.F. Lange: Journal of Crystal Growth, Vol. 259, (2003), p. 103.

[12]K. Sue, K. Kimura, M. Yamanoto, K. Arai: Materials Letters, Vol. 58, (2004), p. 3350.

[13]D. Tao, W. Qian, Y. Huang and F. Wie: Journal of Crystal Growth, Vol. 271, (2004), p. 353.

[14]X. Zhang, H. Zhao, X. Tao, Y. Zhao and Z. Zhang, Materials Letters, Vol. 59, (2005), p. 1745.

[15]J. Yu and X. Yu: Environ. Sci. Technol., Vol. 42, (2008), p.4902.

[16] P. Si, X. Bian, H. Li and Y. Liu: Materials Letters, Vol. 57, (2003), p. 4079. 